\title{
The Story of Oh: the aesthetics and rhetoric of a common vowel sound
}

\section{Dominic Symonds}

'Every sound is a bundle of different qualities'.

(Van Leeuwen 1999: 145)

\begin{abstract}
This article investigates the use of the 'word' 'Oh' in a variety of different performance idioms. Despite its lack of 'meaning', the sound is used in both conversation and poetic discourse, and I discuss how it operates communicatively and expressively through contextual resonances, aesthetic manipulation and rhetorical signification. The article first considers the aesthetically modernist work of Cathy Berberian in Bussotti's $\mathrm{La}$ Passion Selon Sade: then it considers the rhetorically inflected use of 'Oh' to construct social resonance in popular song; finally, it discusses two important uses of the sound 'Oh' which bookend the Broadway musical Oklahoma!, serving to consolidate the allegorical and musico-dramatic narrative of the show.
\end{abstract}

Keywords:

$\mathrm{Oh}$ signifying practice

Oklahoma!

vowel

signification

rhetoric

When Sylvano Bussotti adapted Pauline Réage's novel The Story of O (1954) into music in La Passion selon Sade (1966), it was the enigmatic 'O' that formed its basis. The piece characterizes O, an amalgam of de Sade's characters Justine and Juliette, through the stylized vocal experimentations of singer Cathy Berberian. Its text comes from a sixteenth century sonnet by Louise Labé, 'Ô beaux yeux bruns, ô regards destournez' (1555), 'whose obsessively repeated “O”s serve Bussotti as a constant echo of Réagé's [sic] heroine' (Osmond-Smith 2004: 11). Its unusual figurative score (looking more like a mathematical diagram than a conventional piece of musical notation) clearly emphasizes the letter ' $\mathrm{O}$ ' in various sizes and fonts, and one assumes 
that it directs the performer to interpret vocally the typography of the document, 'unmediated by the specifics of vocabulary or grammar' (Osmond-Smith 2004: 8). Berberian's recording of the piece (Berberian 1988) — in a way its definitive recording, since this piece was written with her voice in mind and recorded under the direction of the composer—privileges the sound of the letter ' $\mathrm{O}$ ' through Berberian's trademark sounds: snatches of different languages; sounds suddenly severed as if crudely edited on tape; erratic jumps in pitch apparently mimicking a sonic oscillator; ${ }^{1}$ sung 'O's specifically pitched; breathy spoken 'O's falling or rising in pitch; extreme though unspecific emotional intensity channelled into the sound of the voice:

There is no 'meaningful' or significant text which is then 'set' to music but a musico-phonetic 'text' which belongs to no particular kind of human language and does not result from the transformation or deformation of a language. This 'text' has no semantic meaning but it does have a high emotional content; the basic expressiveness of human sound communication has been developed into an independent 'sound composition'. The actual musical composition and the 'sound composition' form an indivisible whole; the text is communicated through the music and the music through the text. The instrumental setting does not 'accompany' the vocal line: the various instruments are used in such a way that they complement and set off the human sounds so that the phonetic composition spills over into the sound composition. The action may well be considered enigmatic, though its expression of human character and behaviour

\footnotetext{
${ }^{1}$ Berio's directorship of the Studio di Fonologia Musicale oversaw the construction of a studio with nine oscillators designed to enable complex recording techniques. Berberian was nicknamed the 'tenth oscillator' (Osmond-Smith 2004: 4).
} 
does make dramatic sense; it is, though semantically incomprehensible, nevertheless emotionally a clearly understandable musico-phonetic structure.

(Ligeti, cited in Bornoff 1968: 47-8)

This experimentation with the materiality of vocal sound has been a surprisingly common feature of modernist arts throughout the twentieth century, and there is a remarkable wealth of study crossing disciplines and languages. The poet Robert Frost, for example, refers to the 'sentence-sound', the 'sound-posture', 'vocal-gesture', and 'the sound of sense' (Newdick, 1937: 290):

What I am interested in emphasizing is the sentence of sound, because to me, a sentence is not interesting merely in conveying a meaning of words; it must do something more; it must convey a meaning by sound.

(Newdick 1937: 293)

This is an intriguing invitation that makes us think of the iconic and sometimes indexical uses of sound; though we sense that Frost is referring to something else that is harder to pin down in the terminology of formal linguistics and that appears to be generated outside of its accepted operations. Such a distinction is discussed in detail by Jakobson \& Waugh, who reveal not only 'the tendency for sound to have an indirect, or mediated, relation to meaning [but also] its tendency to have direct, and thus immediate, signification' (Jakobson \& Waugh 2002: 4); elsewhere, Dany Nabus distinguishes 'the meaningful function of sounds [from] their anatomo-physiological basis' (Nabus 2003: 50), drawing a distinction between 'meaning' and something more 
nebulous which nevertheless bears communicative energy. For others, the term 'textsound':

characterizes language whose principal means of coherence is sound rather than syntax or semantics - where the sounds made by comprehensible words create their own coherence apart from denotative meanings.

(Kostelanetz 1977: 61)

Sound Poets such as Steven McCaffery consider the sound of a word to offer 'a more basic connection between an object and its sign [than symbolic meaning], a connection predicated upon the efficacy of the sonic as a direct, unmediated vector' (McCaffery 1978). Insofar as the sonic vector might be determined 'musical', this reminds us of similar distinctions that have been drawn between words and music: 'an unmediated, authentic, primitive language that could "say" all that words could not' (Smart 2004: $15)$.

This interest in the sound of language - seeing beyond (or rather hearing beyond) its privileged symbolic signification to explore the resonances of its materiality ${ }^{2}$ - enables an encounter with language that is to some extent de-symbolized, but which on the other hand reveals aspects of the sonic utterance that are inculcated in a communicative act: uses of tone, timbre, rhetoric, prosody, style, rhythm etc. that trade on shared, if not lexically defined, codes. On the other hand, these other elements of the sound figure, whilst redundant in the conventional understanding of what the 'symbolic' relationship is, and whilst themselves being sometimes iconic, play vital

${ }^{2}$ Edward Sapir urges us to read poetry 'with the ear, never with the eye' (Sapir 1949: $501)$. 
parts in other symbolic formulations of signification. Jakobson \& Waugh discuss many of these in The Sound Shape of Language', and their example of 'magnitudesymbolism', borrowed from Edward Sapir, will serve to illustrate this discussion: 'certain vowels and consonants "sound bigger" than others' (Jakobson \& Waugh 2002: $188)^{4}$ - an associative connection that inevitably aids linguistic communication in complex ways. Hamlet, for example, specifically says ' $O$, that this too, too solid flesh would melt [...]' (Hamlet, Act 1, scene 2) rather than 'Ee', 'Ai' or 'Ooh'-and though the sound is lexically meaningless, its weight and depth seem greater than these alternatives: it is in part its sound that connotes the sombre contemplation appropriate for this scene.

Formal linguistics trades off a spatio-temporal metaphor in which the hermeneutic placement of discrete units diachronically and synchronically formulates meaning through double articulation, a limiting though practical concept that allows analogous basic principles for both spoken and written language. The meaning of complex structures (i.e. sentences) is generated through, on the one hand, a diachronic choice of each symbol distinguished in 'sense-discrimination" from other approximate symbols; and on the other hand, a chain of synchronous symbols providing subsequent contextual information and again narrowing meaning possibilities down through distinction. Jakobson \& Waugh, however, prefer to consider the signification of sound units (i.e. phonemes used as in speech) not only within the parameters of double articulation but also within a matrix of wider influencing factors. Their study, with its

\footnotetext{
${ }^{3}$ See particularly Chapter 4 and Appendix 2.

${ }^{4}$ Jakobson \& Waugh take this idea from Sapir's article 'A Study in Phonetic Symbolism’ (Sapir 1949: 61-72).

${ }^{5}$ This is a phrase used throughout Jakobson \& Waugh.
} 
'recognition that everything in the speech sound plays some linguistic role' (Jakobson \& Waugh 2002: 2) recognizes multiple symbolic and associative (i.e. expressly not arbitrary) connotations in the speech figure, and indicates that meaning-making is generated not exclusively through the structurally encoded articulations of formal linguistics. To Julia Kristeva, one fault of formal linguistics is that it has a blind spot to anything other than 'epistemological purity' (Kristeva 1986: 26), whereas so-called spontaneous discourse is often 'motivated' (Kristeva 1986: 91): deliberately coloured by rhetoric, style, or hint. The manipulation of these expressive factors, readily habituated into standard practice, becomes assimilated into poetic discourse, and it is this - the use of the sound shape of language to signify in the poetic discourse of song - that I would like to discuss in relation to the sound (sounds? word?) 'Oh'. Jakobson \& Waugh introduce us to poetic discourse as 'the most important locus of linguistic creativity' (Jakobson \& Waugh 2002: 5), drawing particular attention to 'the direct interplay of sound and meaning [...] in poetry' (Jakobson \& Waugh 2002: 4). Not only are they referring to the poetic use of language - mechanisms such as onomatopoeia and alliteration that self-consciously play with the materiality of sound, and which elsewhere have caused critics to refer to the "wild joy in the sheer sound of words' (Sapir 1949: 501) ${ }^{6}$ - but they are also referring to the structural controls of rhythm and rhyme that impose an 'ad hoc [...] organization of the verbal sound matter' (Jakobson \& Waugh 2002: 219). In short, the exigencies of poetic discourse at once deliberately construct sound into patterns and mediate the communicative spontaneity of conventional language. Jakobson \& Waugh discuss certain forms of poetic discourse, referring to Saussure's Poetique Phonisante and an extended analysis of a poem by e. e.

\footnotetext{
${ }^{6}$ Edward Sapir's comment is from his review of a Gerard Manley Hopkins anthology from 1921.
} 
cummings, but their otherwise exhaustive consideration of 'sound shape', perhaps surprisingly, does not extend to a consideration of poetic discourse in performance, with its own influencing factors.

That sound affects 'meaning' in performance was evidenced even by Stanislavski in experimental exercises with opera singers (Magarshack 1986: 391) and in a production of the French play Lili, which was performed in Russian but which used the cadences of French speech, to unintelligible effect (Magarshack 1986: 45).

Elsewhere, Peter Brook's Orghast project with Ted Hughes further explored the nexus of sound and meaning, asking: 'What is the relation between verbal and non-verbal theatre? What happens when gesture and sound turn into word? What is the exact place of the word in theatrical expression? As vibration? Concept? Music?' (Smith 1972: 42):

Is there another language, just as exacting for the author, as a language of words? Is there a language of actions, a language of sounds - a language of word-as-part-of-movement, of word-as-lie, word-as-parody, of word-asrubbish, of word-as-contradiction, of word-shock or word-cry?

(Brook 1996: 49)

This article offers a study into the sound of language, focussed on the 'word' 'Oh' and seeking to find the sense of this word not in a semantic definition, but in an understanding of the many ways in which the sound can be caused to 'mean'. That I have assumed an engagement with music is no coincidence, for a discussion of words as sounds naturally finds sense in qualities of speech like pitch, stress and tonality. That I have assumed an engagement with performance introduces social and environmental levels of articulation, in which the speaker (constructed to varying degrees) contextualises his/her utterance within various contexts (constructed to varying 
degrees). I have chosen the word 'Oh' because it seems to be a non-sense (non-lexical) word and is therefore particularly resonant for the purpose of exploring extra-linguistic signification.

The article will first consider the nature of 'Oh' in terms of linguistics and phonetics; this will lead to a discussion of the perhaps more implicit rhetorical use of vocal sound where 'Oh' serves as an informal, though fundamental, performative signifier in popular performance. Finally, I will consider the allegorical and musicodramatic use of 'Oh' in the musical Oklahoma!.

\section{'Oh'}

'Oh' might best be considered a phoneme, 'a family of sounds' (Jones in Fudge 1973: 27); 'a normal sound of the language together with all its incidental variants' (Fudge 1973: 24). There are approximately 40 phonemes in the standard English language (Ward 2006: 34), including the other common vowel sounds. The purest form of 'Oh' (the 'normal sound') might be represented by the phonetic symbol/o/, though its precise pronunciation is of course grossly affected by all manner of allophonic variations - regional, dialectal, aesthetic and rhetorical influences - that distance the utterance acoustically from the abstraction of the pure phoneme /o/. Murray Schafer links sounds such as these with the very physicality that is required to produce them: 'if the mouth is wide open you can't produce any other sound' (Murray Schafer 1979: 8), he says of /a/; his comment about/o/ is similar: 'it suggests roundness and perfection' (Murray Schafer 1979: 9). Such roundness roughly describes the shape of the mouth in articulating /o/: the tongue moves backwards, the soft palate arches upwards to create a hollow inside the oral cavity, and the lips purse to almost close the hollow at the front of the mouth. This, and the accompanying modification of the pharynx, gives the 
resonating chambers a particular shape responsible for the characteristic formants of /o/: a low formant in the pharynx of approximately 500 hertz $^{7}$ and a high formant in the mouth of approximately 850 hertz $^{8}$. His invocation of 'perfection' points to an acoustic purity consistent with the 'normal sound' of the monophthong /o/, and perhaps relates to the fact that the sound enjoys a peculiar closeness of low and high formants ${ }^{9}$. Nevertheless, the 'normal sound' of /o/ is unusual in English, with the International Phonetic Alphabet recognizing it as the 'normal sound' for 'Oh' only in Scottish English, where the open sound is formed towards the back of the mouth and remains open. Irish and Welsh English both tend to follow this open sound with a subtle closing of the lips /o:/: General American and Canadian involve a more pronounced closure and move towards the diphthong /ov/; the placement of 'Oh' in Received Pronunciation begins more centrally and is commonly interpreted as the diphthong/əv/, a moving

\footnotetext{
${ }^{7}$ Different vowel sounds are created by soundwaves resonating at different frequencies within the cavities of the vocal apparatus (mouth, pharynx, etc.). Key frequencies at which these resonances occur are known as formants, and the frequencies are measured in cycles per second (cps) or hertz.

${ }^{8}$ These approximate values are given by Murray Schafer (1979: 14); a perhaps more scientific study (Wells 1962: 'Frequencies', Table 2) puts mean values at 449cps and $737 \mathrm{cps}$ respectively. The precise value for an individual's speech will be dependent on gender, physical apparatus, habitual placement, accent, and moderating factors which we shall discuss.

${ }^{9}$ By contrast, Ladefoged reports a span of $220 \mathrm{cps}$ to $2300 \mathrm{cps}$ between low and high formants of his sound /i/ (Ladefoged 1966: 92).
} 
vowel that starts with the open, hollow, pure sound but glides towards the velar closure of $/ \mathrm{u} /$.

Scientific studies into the use of the sound 'Oh' in (American) English recognize it as a 'non-lexical conversational sound' (Ward 2006): it is a 'discourse marker' (Fox Tree \& Schrock 1999) or a 'response cry' (Goffman 1978) that has not formally been classified symbolically, but its use within speech carries communicative potential. Language specialists list some seventeen functions of 'Oh', including its use to add emphasis, to indicate an upcoming emotional or evaluative utterance, and as a ‘floor-keeping device' (Fox Tree \& Schrock 1999: 281). Almost all of these functions, however, are recognized in one broad category:

speakers say oh to let their addressees know that the speaker's model of the communicative exchange is undergoing a change of state. This change of state often comes about from new information, such as new facts or new perspectives on prior information.

(Fox Tree \& Schrock 1999: 281)

The 'new information' thesis is supported by Nigel Ward's study of conversational sounds, where 44 out of 46 instances of the sound ( 96 per cent) correlate to this expectation (Ward 2006: 24). Ward's survey includes associated sounds such as 'Ooh' and 'Oa', but distinguishes between the subtly different ' $A$ ' sound and the sound of the neutral schwa ${ }^{10}$. While 'Oh' is used to process new information, 'A' suggests

\footnotetext{
${ }^{10}$ The schwa is the term given to the neutral vowel utterance formed when the mouth is in a relaxed position.
} 
familiarity, and the schwa ambivalence (Ward 2006: 24). Ward also explains the relationship of 'Oh' to variations of 'Okay' as follows:

okay seems to share with oh some element of meaning[...], and this is likely due to the shared /o/. This is seen by the fact that the newness is downgraded in cases where the /o/ is reduced to a schwa (ukay [...]), elided completely (kay) or replaced by a nasal (m-kay, n-kay and unkay). On the other hand, where the newness of information is significant, the /o/ is lengthened or repeated, forming ookay [...] or oh-okay.

(Ward 2006: 24)

This judgment has considerable significance for our study, because it suggests that, despite their lack of semantic or symbolic signification, non-lexical conversational sounds such as 'Oh' carry intrinsic meaning subconsciously invested at a pre-articulate level and 'largely predictable from the sounds' (Ward 2006: 34).

This should not surprise us, since it supports Kristeva's understanding of how the semiotic informs the symbolic. Briefly, she claims that the formal construct of language (the phenotext) is forever targeted by pre-rational and instinctive 'drives' (the genotext) which disrupt the formality but generate meaning beyond pure semantics (Kristeva 1986). Elsewhere, research into the brain has suggested that the two hemispheres supervise very different aspects of language (distinctive features and significative features); the suggestion is that formalized and symbolic encodings take place in the left hemisphere while physiognomic and emotive colouring is provided by the right (see Jakobson \& Waugh 2002: 263-4). In terms of our discussion, the precise role of sound in the communication of meaning is therefore seen to be linked to 
tensions between the symbolic and the semiotic, and between the left and right hemispheres of the brain; such tensions become particularly resonant in the case of nonlexical conversation sounds such as 'Oh' whose hermeneutic meaning is somewhat indeterminate but which are nevertheless used as words (discourse markers) within the constructions of language.

The ramifications of this for poetic discourse — and particularly song — are interesting, given the fact that poetic discourse is more acutely structured and preconceived than conversational discourse. Kristeva suggests that poetic language makes use of the semiotic through the poet's capacity to access-however subconsciously_-the 'semiotic disposition':

the various deviations from the grammatical rules of the language [such as] articulatory effects which shift the phonemative system back towards its articulatory, phonetic base and consequently towards the drive-governed bases of sound-production.

(Kristeva 1986: 28)

Roland Barthes has famously adapted Kristeva's theories to discuss song, ${ }^{11}$ and again, in the example he uses, the encounter of the symbolic with the semiotic is subconscious. Nevertheless, given the fact that stylized physiognomic and emotive colouring forms a part of the preconceived structure of poetic discourse, particularly in performance (in the intonation of a melody, for example), we might hypothesize that poetic discourse consciously uses and indeed iconizes certain features of conventional

${ }^{11}$ In 'The Grain of the Voice', Barthes 1977. For a more thorough discussion of this see Symonds 2007. 
discourse that are otherwise encountered as instinctive or subconscious (motivations, semiotic urges). In this respect, the assimilation of semiotic patterns into symbolic behaviour and the transference of encoding functions from right to left hemisphere are a fundamental part of the poetic utterance, and play a not insignificant role in the communicative-expressive act.

I would like now to consider how the various significative features of sound are built into the constructed material of song, both by performers and writers. In the performative space of popular music these elements are brought into signifying practice in order to establish the social identity of the performer-character; in the performance script of musical theatre these elements are stylistically appropriated in order to dramatize specific characters within their diegetic environment.

\section{The performative 'Oh' in popular music}

The use of 'Oh' in song lyrics takes on an interesting dual function. As a 'word' within the formally drafted lyrics — 'Oh! You beautiful doll!'12 ' 'Oh baby, that's what I like!' ${ }^{13}$, 'Oh my love ${ }^{14}$ — it finds resonance from its context (exclamatory, emphatic, emotive, etc.), and operates very much as a textual element that therefore 'means' very much like a word (i.e. a symbolic signifier) connoting, respectively, exclamation, emphasis or emotion. A second function arises from its semantic opacity in performance, in which the interplay between various tensions (word and non-word; the symbolic and the semiotic; the formal phoneme and its disruption; the conscious and the subconscious) becomes fundamental to signifying practice.

\footnotetext{
${ }^{12}$ From Ayer \& Brown's 1911 song of the same name.

${ }^{13}$ From the 1958 Big Bopper hit 'Chantilly Lace'.

${ }^{14}$ From the much-recorded 1936 Hy Zaret song 'Unchained Melody'.
} 
Studies of popular song recognize this process in their invocation of Kristevan theory: Brent Hayes Edwards' discussion of scat in Louis Armstrong's work, for example, notes it to be a 'falling away from the word', in which 'an entirely new approach to the singing voice is discovered in the breach, in the exigencies of musical time' (Edwards 2002: 620).

Such a sequence replaces 'arbitrariness' with 'articulation' [and] restores to formal linguistic relations the dimensions (instinctual drives) and operations (displacement, condensation, vocalic and intonational differentiation) that formalistic theory excludes.

(Kristeva 1986: 91)

Let's consider some examples in which the disruption of the normative, the tension between word and non-word, or the conscious employment of semiotic features is perhaps most evident. Michael Daley analyses the singing style of Blues singer Robert Johnson, noting in his recording of 'Sweet Home Chicago' (1936) variations on the syllable 'Oh' 'from [o] to [ou] to [ow], with every point in between' (Daley n.d.).; he categorizes Johnson's use of a 'kissing' voice as one of four general voice types used, and observes the habitual tendencies of this style to affect Johnson's pronunciation ('lips extruded [...] reduced tongue movement and thus duller

\footnotetext{
${ }^{15}$ Of course, examples such as this are necessarily difficult to translate into the symbolic strait-jacket of academic language, though systems have been established that use diacritic markings (Daley 2007), spectral imagery (Cogan 1984) and even scorebased notation (Daley 1997) to attempt to represent a full phonetic interpretation of such sounds.
} 
articulation of consonants [...] increasing upper midrange frequencies in the voice', Daley n.d.). Whilst he does not hypothesize the social encoding implicit in this vocal technique, other theoreticians interpret such Blues vocality as being implicitly linked to a presentation of ethnicity. Richard Middleton's discussion of the vocal 'mask', a performance of complex selves which is heard in the 'tissue of voices' (Middleton 2006: 56), recognizes the 'deeply-layered, uncompromising dialogics' (Middleton 2006: 80) of blues vocality which causes us to ask 'whose voice(s) do we hear[?]' (Middleton 2006: 43), 'as if there were another voice inside there somewhere' (Middleton 2006: 60). Here the discussion recognizes that these 'articulatory effects', paralinguistics or non-lexical sounds are consciously employed to construct particular social resonances, based on our use of sound within conventional discourse. Elsewhere, Daley also notes expressions of identity in Patti Smith's recording of the Van Morrison track 'Gloria', in which 'she appropriates both masculinity and femininity for playful deconstruction' (Daley 1997: 237) through 'dramatic' and 'rhetorical control' (Daley 1997: 238) of her vocal expression. Meanwhile, in 'The Beautiful Ones' by Suede (Anderson \& Oakes 1996a), Brett Anderson's pronunciation of 'Oh' seems to slide through all points between /a/ and /u/. His vocal sound — already distorted technically_ starts with a confrontational and mannered yell from the depth of his throat, somewhat stifled by a tongue pushed further back than is usual. As the tone changes and passes through the very wide, open 'Ur-sound' (Murray Schafer 1979: 8) of /a/, a more conventional /o/ and the neutral schwa, his mouth shape changes accordingly to finish in pouting lips, a show of coy playfulness. His vocal performance of 'Oh' is hugely exaggerated, physically reflective of the internal vowel movement and expressive of an 
identity that challenges both the conformity of the 'normal' and the conventional signifiers of vocal and sexual expression. ${ }^{16}$

Thus in departing from a purity of sound - in the 'ripple and curve' (Murray Schafer 1979: 21) of the sound away from its expected placement-possibilities of social and environmental signification emerge. Although 'Oh' may lack semantic precision, it is clearly used in performance to signify, as Fornäs illustrates:

Nonsensical utterances may actually be heard as meaningful in a given intratextual context $[\ldots]$ Anything that is vocally uttered may in principle enter the realm of verbality and become at least potential words, just as everything in what is socially coded as a musical performance may be heard as music.

(Fornäs 2003: 46)

Accordingly, Christophe den Tandt's study of semi-articulation in early rock 'n' roll lyrics ('A wopbopaloobob alopbamboom', for example) links this sublinguistic wordplay to a social statement, the 'refusal of adulthood' (den Tandt 2001: n.p) that is immediately evident in rock ' $n$ ' roll culture, and which den Tandt sees in Kristevan terms:

Rock's vocals bring into play the pre-oedipal component of the geno-text - its status as baby-talk, as tool of interaction with the mother $[\ldots]$ a return to

\footnotetext{
${ }^{16}$ It is interesting to see how Anderson's performance style develops over several years to perform different variations of his own persona and different relationships with the familiar song (Anderson \& Oakes 1996b, 1997, n.d., 2003).
} 
boyishness or even babyhood. Such a vocal regression is appealing [...] because it connotes transgressive teenage fun, the refusal of adulthood.

(den Tandt 2001: n.p)

The intratextual contexts are many (genre, character, identity, habitus, etc.), and while the various examples above offer very different contexts — broadly adopting signification relating to race, gender and sexuality — the performative rhetoric of each and our contemporary reading of all is cumulative and adaptive, building on an informal rhetorical lexicon established through our immersion in and social use of popular music.

The rhetorical signification I have indicated in the expressive rhetoric of avantgarde music theatre (Berberian) and the social rhetoric of popular music (Johnson, Smith, Anderson) shows extreme manipulation of the 'normal' sound 'Oh'. I have discussed how the materiality of the sound and its manipulation are used to construct the performance personality of the performer-character. In the final part of this article, I would like to look at the use of 'Oh' within a further constructed context, to see how the conscious placement of that material sound within a musical theatre framework musico-dramatically constructs the identity of characters within their diegetic environment.

\section{The musico-dramatic function of the speech sound in musical theatre}

I would like to turn to two important uses of the sound 'Oh' that bookend Oklahoma!: Curly's opening solo 'Oh, What a Beautiful Mornin', and the rousing choral climax of the title song, 'Oklahoma'. 
The use of 'Oh' in both songs is significant, and deliberately emphasized: both Fordin (1995: 188) and Hyland (1998: 140) indicate that Hammerstein spent considerable time 'fussing' over whether to use the word 'Oh' in the lyric of the opening number; whilst the dramatically elongated use of the sound in the title number, extended over almost two-and-a-half bars, is clearly self-conscious ${ }^{17}$. In both examples the use of 'Oh' takes on the expressive exclamatory gesture of poetic discourse: 'Oh, What a Beautiful Mornin', for example, is referred to as 'a tiny tone poem on dawn in God's country' (Mordden 1999: 73). It is a paean to the pastoral, which Tim Carter discusses in relation to music:

In the pastoral, simple countryfolk live a life of bliss and innocence supported by bountiful nature, at one with their lives and with the world. They sing as if music were a natural language.

Of course, 'Oh' is not the opening lyric in this song, which starts with a preliminary, unaccompanied verse. Nevertheless, it is set up in the music as the significant moment at which the song begins in earnest: previous instrumental material, reminiscent of bird-

\footnotetext{
${ }^{17} \mathrm{I}$ am indebted to an anonymous peer reviewer of this article for drawing my attention to another striking use of 'Oh', in Mark Blitzstein's The Cradle Will Rock (1937). Larry Foreman, the union organizer, is summoned to speak out in the musical number 'Leaflets' (also known as 'Which of You Guys') and this use of 'Oh', the only pitched tone following an otherwise highly rhythmic but unpitched Sprechstimme, is sustained for several seconds, making it particularly significant to the musico-dramatic context of the number.
} 
song, has left a dominant bell-tone hanging in the air for sixteen bars; our expectation of a resolution to the tonic is heightened once the orchestra enters in the twelfth bar.

At the end of the show 'Oklahoma' builds up its exclamation of 'Oh' in a similar way: a simplistic preliminary verse culminates in repeated Ds in the melody the suggestion of the dominant, anticipating a resolution to G. Immediate resolution is confounded by a sudden key change to D flat, but while this magnifies the tension, it also heralds imminent resolution in its quickened pace, its four-bar crescendo and its forceful scalar climb through two octaves to arrive at the sustained high tonic 'Oh'. 'Oh', as we have seen, is considered to express 'new information, such as new facts or new perspectives on prior information' (Fox Tree \& Schrock 1999: 281), so it is surely not just coincidence that 'a major characteristic of Oklahoma! [is] its insistent theme of new beginnings and fresh starts [...] seen in the exhilarating music of the title song' (Donovan 1974: 486). This 'Oh' extends into seven bars in all, with the female chorus voices emulating wind sweepin' down the plain in a kitsch celebration of the new state being founded, the new couple at last uniting, and the new show drawing to its conclusion. And this 'sound' 'Oh' is enormously playful: immediately the volume dips to piano, and Curly enjoys its exclamatory vigour. This 'Oh' is the sound of 'roundness and perfection' (Murray Schafer 1979: 9), and we anticipate it to be the beginning of an exclamation of joy: 'Oh, What a Beautiful Mornin', perhaps. When the sound is cut short at the beginning of the third bar with the crack of a $/ \mathrm{k} /$ and a complete crotchet break, our expectation is confounded, and the collaborators meta-theatrically mock us, establishing a connection between performer and audience (and between the writers and the audience): far from meaningless, though, this 'Oke' is the first syllable of 'Oklahoma'. When the joke is replayed, this time up a semitone and sung by the whole company, the audience is able to share it. 
Both numbers site the lyric 'Oh' above tonic chords, contributing to 'the impression of folklike simplicity' (Swain 2002: 94). This is a characteristic of Rodgers' writing (Hyland 1998: 161) and in functioning to resolve preceding tensions with such a stable and comforting tonic (tensions in the music mirroring tensions in the land ${ }^{18}$ ), the framing of the show in these two powerful 'Oh' sounds consolidates feelings of contentment, natural balance and community.

Hammerstein's use of language is celebrated for its 'rural patterns of American speech' (Mast 1987: 207), and the word 'Oh', as I have reported, is a common discourse marker in vernacular American language. Critics recognize this in ' $O$, What a Beautiful Mornin', speaking of the 'vernacular directness' of its lyrics (Nardin 1958: 24), and the 'extemporaneous' suggestion of its music (Mast 1987: 207). As Carter reports, this sense of the vernacular - and significantly the sense of the "poetry and the rhythms of speech' (Carter 2007: 10); 'the beautiful rhythmic utterance' of the American language (ibid: 11) — is something that had interested Lynn Riggs, author of the source novel Green Grow the Lilacs. That this vernacular spontaneity adds to the idea of the individual and the pastoral is significant and sets up a counter to which the communal sung 'Oh' of 'Oklahoma' later responds: as Andrea Most asserts, 'the individualism of the line "Ev'rythin's goin' my way" becomes a communal celebration of "our way", (Most 1998: 80).

Nevertheless, as Steyn observes, the words of the lyrics alone do not carry the dramatic resonance that they do as song (Steyn 2000: 24). It is neither the words nor

\footnotetext{
18 'The tension in the song is [...] increased as the bass line becomes chromatic, and as the last phrase sustains a prolonged dominant harmony under the repeated Bs of the melody' (Swain 2002: 90-91).
} 
music in isolation that contribute to the effect; together, they 'transform the simplistic plot into a near-magical myth' (Donovan 1974: 480), and in this, Rodgers \& Hammerstein's deft use of the semiotic framework (the signifying practice) of musical theatre 'found a way to do what poetic drama had always done - to make time stand still while the audience looks inside a character and is told explicitly, in imaginative language, what the character feels' (Nardin 1958: 24). Specifically, the show dramatizes the land organization and 'civilization' of western territories into States and deliberately situates its characters within that social and environmental diegesis through a careful use of the musico-dramatic semiotic framework. While the politics merely bubble away under the surface of the narrative, we can see in the musico-dramatic dynamic a tension between freedom and order that constitutes the organization of this politics, particularly in the trajectory from the 'Oh' of 'Oh, What a Beautiful Mornin'" to the 'Oh' of 'Oklahoma'. The first — the solitary voice of a lone figure in the wilderness — is solo, lightly accompanied on strings, free and pastoral, a dominant in the melody above the simple and earthy tonic; the second - the rousing choral cheers of a whole community united in a shared endeavour-is communal, triumphal and metrically controlled - the 'ringing affirmation' (Steyn 1999: 82) of a tonic resolution. Improvements in the status quo are seen as being civilising manoeuvres, and ideologically normative behaviour — settling down, sharing, marriage — is seen to be rewarded.

This civilizing shift from individual to community, then-key to one central mythology in American identity and relating to the move from frontier settlement to societal organization - is rhetoricized discretely in the trajectory from 'Oh' (What a Beautiful Mornin') to 'Oh' (-klahoma). Before the song 'Oklahoma' is even over, however, the representation of these people (as civilized) changes and a subtle, though 
ideological, revisioning, perspectivizes this grouping not just as a jubilant celebration of communitas, but as the sound of an ordered society; a society whose territory is fenced off and which operates the rule of law, a society of owners of land: an economic society. And much of the signification of this economic society is effected through the handling of phonemic sound units in the arrangement of the number by Robert Russell Bennett ${ }^{19}$. The composite of sounds /Oklahoma/ is ruptured and broken apart in the ensemble voices (/Okla/ - /homa/) to create a rhythmic choral soundscape whose machine-like repetition predicts the technological might that capitalist economies are founded on:

Everyone goes through the necessary motions at the conveyor belt, performs a partial function without knowing the entirety.

(Kracauer 1989: 147-8) ${ }^{20}$

The song ends with the whole company spelling out the letters of 'Oklahoma', relishing the formal (ordered, civilized) lexicographical pronunciation of each

\footnotetext{
${ }^{19}$ Interestingly, this trajectory from the pastoral to the economic is reflected in anecdotal accounts of the show's development, particularly in Max Wilk's articulation of how 'Oh, What a Beautiful Mornin'” was conceived (Wilk 2002: 78-9) and 'Oklahoma' orchestrated (Wilk 2002: 200). The initial seeds of inspiration are couched in terms of the pastoral and individual, while the final stages of production are seen in terms of the industrial and faceless production line.

${ }^{20}$ See Kracauer's essay 'Girls und Krise' for further discussion of the chorus line as an aesthetic normalization of the industrial lifestyle (Wollen 1991: 59).
} 
individual utterance before concluding with a harmonized cadence on the full word. It is particularly interesting, though, that this 'ordered' end to the song is then answered with an informal, unpitched yelp: 'Yeow!' Are we to read this as a corruption of the sound of 'roundness and perfection' (Murray Schafer 1986: 181), a semiotic disruption of the now ordered society, an ongoing musico-dramatic manipulation of the strongly signifying phoneme 'Oh'? ${ }^{21}$

The story of 'Oh' is a complex one, and this discussion could be extrapolated to other sounds — non-lexical or not— that are used in both conversational language and poetic language. The fact that 'Oh' is both a formally non-lexical sound free of symbolic meaning and an open vowel sound open to aesthetic and social rhetorical signification has made it a particularly potent tool for musical theatre. In many ways, we might consider the sound 'Oh' as both yet neither words and/nor music, and as both yet neither text and/nor performance. What is clear from all of these accounts is the fact that, despite the removal of certain (what are problematically in this context called) signifiers, our hermeneutic tendency is resilient and urges us towards decoding: as narrative (Lavy, Jakobson \& Waugh), as representation (Borroff's mimetic sound symbolism), as metaphor (Brecht), or as musico-dramatic allegory_organizing concepts that contextualise the object 'Oh' in order to rhetoricize its discrete ambiguity.

\footnotetext{
${ }^{21}$ Finally, the show ends with a reprise of 'Oh, What a Beautiful Mornin'. Whilst this develops into a fairly standard musical theatre reprise, it starts — significantly—without the 'Oh', as if removing from the song its traces of both pastoral simplicity from the opening version and communitas from 'Oklahoma'.
} 


\section{Works cited}

Anderson, B. \& R. Oakes, (1996a), 'The Beautiful Ones', on Coming Up [Audio CD], Nude Records, Nude 6CD.

_ $\quad$ (1996b), ‘Suede - demo’ [promotional video], http://www.youtube.com/watch?v=799FohxIrfc\&mode=related\&search= Accessed 25 July 2007.

(1997), 'Suede- Unscene Part 2’ [televised performance footage], http://www.youtube.com/watch? $\mathrm{v}=\mathrm{g} 4 \mathrm{Dm}$ t0tPEw\&mode $=$ related\&search $=$ 02.20-.3.20

Accessed 25 July 2007.

_ $\quad$ (n.d.), 'Suede - Beautiful Ones (live)’ [live performance footage], http://www.youtube.com/watch?v=Qc9ikBtGCbk Accessed 25 July 2007.

(2003), 'Suede - sessions at AOL' [promotional video], http://www.youtube.com/watch?v=ajSsu ezxkI\&mode=related\&search= Accessed 25 July 2007.

Barthes, R. (1977), Image, Music, Text, London: Fontana Press. 
Berberian, C. (1988), The Many Voices of Cathy Berberian [Audio CD], Wergo, Wer 60054-50.

Block, G. (ed.) (2002), The Richard Rodgers Reader, New York: Oxford University Press.

Bolinger, D. (1946), 'Thoughts on 'Yep and Nope', American Speech, 21:2, pp.90-95.

Bornoff, J. (ed.), (1968), Music Theatre in a Changing Society: The Influence of the Technical Media, Paris: Unesco.

Borroff, M. (1992), 'Sound Symbolism as Drama in the Poetry of Robert Frost', PMLA, 107:1, pp. $131-144$.

Brook, P. (1996), The Empty Space, New York: Simon \& Schuster.

Bussotti, S. (1966), La Passion selon Sade. Mystère de chambre avec tableaux vivants, précédé de solo, avec un couple rara et suivi d'une autre phrase à trois, etc. [Reproduction of the author's original score], Milan: G. Ricordi \& Co.

Carter, T. (2007), Oklahoma! The Making of an American Musical, New Haven \& London, Yale University Press. 
Cogan, R. (1984), New Images of Musical Sound, Cambridge, MA: Harvard University Press.

Daley, M. (1997), 'Patti Smith’s 'Gloria': Intertextual Play in a Rock Vocal Performance', Popular Music, 16:3, pp. 235-253.

_ (2007), 'Vocal Performance and Speech Intonation: Bob Dylan’s 'Like a Rolling Stone', Oral Tradition, 22:1, pp. 84-98.

_ $\quad$ (n.d), "You hear me when I moan": timbre and style in the singing of Robert Johnson', http://www.mikedaley.net/essay robertjohnson.htm Accessed 16 July 2007.

Den Tandt, C. (2001), 'Staccato, swivel and glide: a poetics of early rock 'n' roll lyrics', Soundscapes: Journal on Media Culture, Vol.4, July 2001, http://www.icce.rug.nl/ soundscapes/VOLUME04/Staccato_swivel_glide.shtml Accessed 1 March 2007.

Donovan, T. (1974), “"Oh What a Beautiful Mornin"”: The Musical, Oklahoma! and the Popular Mind in 1943', Journal of Popular Culture, 8:3, pp. 477-488.

Edwards, B.H. (2002), 'Louis Armstrong and the Syntax of Scat', Critical Inquiry, 28:3, 618-649. 
Filmer, P., Rimmer, V. and Walsh, D. (1999), 'Oklahoma!: Ideology and Politics in the Vernacular Tradition of the American Musical', Popular Music, 18:3, pp. 381395.

Fordin, H. (1995), Getting to Know Him: A Biography of Oscar Hammerstein, New York: Da Capo Press.

Fornäs, J. (2003), 'The Words of Music', Popular Music and Society, 26:1, pp. 37-51.

Fox Tree, J. E. and Schrock, J. C. (1999), ‘Discourse Markers in Spontaneous Speech: Oh What a Difference an Oh Makes', Journal of Memory and Language, 40:2, pp. $280-295$.

Fudge, E.C. (ed.), (1973), Phonology: Selected Readings, Harmondsworth: Penguin Books.

Goffman, E. (1978), 'Response Cries', Language, 54:4, pp. 787-815.

Hyland, W. (1998), Richard Rodgers, New Haven and London: Yale University Press.

Jakobson, R. \& Waugh, L. R. (2002), The Sound Shape of Language, The Hague: Mouton de Gruyter.

Knapp, R. (2005), The American musical and the performance of national identity, Princeton and Oxford: Princeton University Press. 
Kostelanetz, R. (1977), 'Text Sound Art: A Survey', Performing Arts Journal, 2:2, pp. $61-70$.

Kracauer, S. (1989), 'The Mass Ornament' [trans. Barbara Correll and Jack Zipes], in: S. E. Bronner, and D. M. Kellner (eds.), Critical Theory and Society: A Reader, London: Routledge.

Kristeva, J. (1986), The Kristeva Reader [ed. Toril Moi], Oxford: Basil Blackwell.

Ladefoged, P. (1966), Elements of Acoustic Phonetics, Edinburgh and London: Oliver and Boyd.

Lavy, M. M. (2001), 'Emotion and the Experience of Listening to Music: A Framework for Empirical Research', Unpublished dissertation, Jesus College, Cambridge University.

Magarshack, D. (1986), Stanislavski: A Life, London \& Boston: Faber \& Faber.

Mast, G. (1987), Can’t Help Singin’, New York: Overlook Press.

McCaffery, S. (1978), ‘Sound Poetry: A Survey', in: S. McCaffery and B. P. Nichol, Sound Poetry: A Catalogue, Toronto: Underwich Editions, available at: http://www.ubu.com/papers/mccaffery.html Accessed 12 March 2007. 
Middleton, R. (2006), Voicing the Popular: On the Subjects of Popular Music, London \& New York: Routledge.

Mordden, E. (1999), Beautiful Mornin': The Broadway Musical in the 1940s, Oxford: Oxford University Press.

Most, A. (1998), "We Know we Belong to the Land": The Theatricality of Assimilation in Rodgers and Hammerstein's Oklahoma!' PMLA, 113:1, pp. 77-89.

Murray Schafer, R. (1979), When Words Sing, Scarborough, Ontario: Universal Edition.

Nabus, D. (2003), 'Lacan's Science of the Subject: Between Linguistics and Topology', in: J-M. Rabaté, (ed.), The Cambridge Companion to Lacan, Cambridge: Cambridge University Press.

Nardin, J. T. (1958), 'Green Grow the Lyrics', The Tulane Drama Review, 3:2, pp. 21-29.

Newdick, R. S. (1937), 'Robert Frost and the Sound of Sense', American Literature, 9:3, pp. 289300.

Osmond-Smith, D. (2004), 'The Tenth Oscillator: The Work of Cathy Berberian 1958-1966', Tempo, 58:227, pp. 2-13.

Rodgers, R. and Hammerstein, O. (n.d.), Six Plays by Rodgers and Hammerstein, (The Modern Library) New York: Random House. 
Sapir, E. (1949), Selected writings of Edward Sapir in language, culture and personality, Berkeley \& London: University of California Press.

Schlesinger, A. M. (1999), The Rise of the City, 1878-1898, Columbus: Ohio State University Press.

Secrest, M. (2001), Somewhere for Me: A Biography of Richard Rodgers, New York: Alfred A. Knopf.

Smart, M. A. (2004), Mimomania: Music and gesture in nineteenth century Opera, London: University of California Press.

Smith, A. C. H. (1972), Orghast at Persepolis, London: Eyre Methuen.

Steyn, M. (2000), Broadway Babies Say Goodnight: Musicals Then and Now, London: Faber \& Faber.

Swain, J. P. (2002), The Broadway Musical: A Critical and Musical Survey, [Second Edition: Revised and Expanded] Lanham, Maryland and Oxford: The Scarecrow Press.

Symonds, D. (2007), 'The corporeality of musical expression: "the grain of the voice" and the actor-musician', Studies in Musical Theatre, 1:2, pp. 167-181. 
Van Leeuwen, T. (1999), Speech, Music, Sound, Basingstoke \& London: Macmillan.

Ward, N. (2006), 'Non-Lexical Conversation Sounds in American English', Pragmatics and Cognition, 14:1, pp. 129-182, available at:

http://www.cs.utep.edu/nigel/papers/pragcog-compact.pdf

Accessed on 25 July 2007.

Wells, J. C. (1962), 'A study of the formants of the pure vowels of British English', MA Dissertation, University of London, available at:

http://www.phon.ucl.ac.uk/home/wells/formants/table-2.htm

Accessed on 3 December 2008.

Wilk, M. (2002), The Story of Oklahoma!, London \& New York: Applause.

Wollen, P. (1991), 'Cinema/Americanism/The Robot', in: J. Naremore and P. Brantlinger (eds.), Modernity and Mass Culture, Bloomington: Indiana University Press. 